http://jmscr.igmpublication.org/home/ ISSN (e)-2347-176x ISSN (p) 2455-0450

crossref DOI: https://dx.doi.org/10.18535/jmscr/v9i11.31

Journal Of Medical Science And Clinical Research

\title{
Primary Fallopian Tube Carcinoma: A Series of 4 Cases and Review of Literature
}

\author{
Authors \\ Dr Meenakshi Rana ${ }^{1}$, Dr Neha Singh ${ }^{2 *}$, Dr Ankita Jamwal ${ }^{3}$ \\ ${ }^{1}$ Junior Resident Department of Obstetrics and Gynaecology, IGMC Shimla \\ ${ }^{2}$ Junior Resident Department of, Obstetrics and Gynaecology IGMC Shimla \\ ${ }^{3}$ Junior Resident Department of, Obstetrics and Gynaecology IGMC Shimla \\ *Corresponding Author \\ Dr Neha Singh \\ Junior Resident Department of Obstetrics and Gynaecology, IGMC Shimla, India
}

\begin{abstract}
Primary carcinoma of fallopian tube is a rare malignancy of female genital tract with incidence of $0.3 \%$ of gynaecological cancers. Here we are discussing a case series of primary fallopian carcinoma in postmenopausal women. The pre-operative diagnosis of fallopian tube carcinoma is very difficult and usually the first diagnosis is made by pathologist. The frequency of fallopian tube carcinoma is very low that its etiopathogenesis, mode and extent of spread is not well understood. Fallopian tube carcinoma is clinically and histopathologically similar to epithelial ovarian carcinoma so the surgical management and chemotherapy follow the same concept. The early diagnosis of fallopian tube carcinoma lead to better management and improved survival rate. During diagnosis both ovaries and fallopian tubes may appear grossly normal on examination. Lymphatic spread in the fallopian tube carcinoma is of more relevance than ovarian carcinoma. In this series we are discussing presentation, diagnosis, treatment followed in these patients and follow up.

Keywords: Primary fallopian tube carcinoma.
\end{abstract}

\section{Introduction}

Primary fallopian tube carcinoma (PFTC) is an uncommon tumor of fallopian tubes accounting for $0.3 \%$ of all cancers of female genital tract. It is very difficult to diagnose preoperatively because of its non-specific symptomatology.

Histologically features and behaviour of fallopian carcinoma as simillar to ovarian cancer. it is possible that the true incidence of PFTC is under estimated because PFTC may have been mistakenly identified as ovarian tumor during initial surgery or during microscopic examination by the pathologist. There is growing evidence to suggest that many high grade serous carcinomas of ovary may prove to arise from fimbrial end of fallopian tubes. PFTC are common in fifties and sixties. The aetiology of this tumor is unknown, suggested to be associated with chronic tubal inflammation, infertility, tuberculosis, salpingitis, tubal endometriosis. Women with mutation in BRCA1 and BRCA2 are at high risk for developing fallopian tube carcinoma so prophylactic bilateral salpingo-oopherectomy done in these patients. PFTC classically present with a triad of prominent watery vaginal discharge (hydropstubaeprofluens), pelvic pain, pelvic mass. 
The triad is noticed in only $15 \%$ of patients. Most common symptom is vaginal discharge or bleeding and noticed in about $50 \%$ patients of PFTC. Pelvic mass on examination is noticed in $60 \%$ of patients and ascites present in advanced disease. Tubal cancers spread by transcoelomic exfoliation of cells that implant throughout peritoneal cavity. lymphatic spread to para aortic lymph nodes and pelvic lymph nodes is common. CA-125 is the most commonly used as $80 \%$ patients with PFTC have elevated pretreatment serum level of CA-125. Here we are discussing four cases of PFTC ancountred in recent years with presentation, diagnosis, treatment in our hospital.

\section{Case 1}

Mrs A 51 year old P1+1, Last child birth $28 \mathrm{yr}$ back was admitted to Kamla Nehru state hospital for mother and child, Shimla on 28-03-08 with complaint of pain lower abdomen for 3 years which was dull continuous and radiating to back .she had discharge per vaginum which was foul smelling whitish yellow in color. She was a menorrhagic for last 9 months. On per vaginum examination there was a mass $8 * 8 \mathrm{~cm}$ in size, mobile in front of uterus. $\mathrm{Hb}$ was $12.3 \%$, LFT, RFT were normal. CA-125 was $152 \mathrm{u} / \mathrm{ml}$. usg and CT scan abdomen showed right tubo-ovarian mass with cholelithiasis. Staging laparotomy, peritoneal washing with total abdominal hysterectomy with bilateral salpigo-opherectomy, infracolic omentectomy was done . Uterus, both the ovaries, right tube was normal, left fallopian tube was replaced by a fungating necrotic growth $8 * 8 \mathrm{~cm}$ in size and stage was 1c. histopath report showed endometroid carcinoma, poorly differentiated with serosal rupture and venous/lymphatic invasion . she was discharged on 24-8-08. Post operative period was uneventful .she was given chemotherapy (cisplatinum+ cyclophosphamide) 6 cycles.

\section{Case 2}

Mrs B 55 year old p3+0, last child birth 33year back, postmenopausal, was admitted to Kamla Nehru state hospital for mother and child, Shimla on 26-03-13 with complaints of discharge per vaginum for $2 \mathrm{yr}$ which was watery, non foul smelling . she had bleeding per vaginum for $1 \mathrm{yr}$, spotting for 1-2 days last episode was 1 month back, patient also had low-backache for 6 month dull aching. On per vaginum examination there was a mass of $6 \mathrm{~cm}$ in size. Hb 9.9gm, LFT, RFT was normal. CA-125 was $1710 \mathrm{u} / \mathrm{ml}$. usg show right adenexal solid cystic mass and MRI showed heterogenous mass in pelvis with pyoslapinx with prominent para aortic lymph node? malignant ovarian mass. Staging laparotomy, peritoneal washing with total abdominal hysterectomy with bilateral salpingo oophorectomy, omental biopsy done. Uterus on cut section had two fibroids, evidence of hydrosalpinx in right tube, tumor arising from left fallopian tube $7 * 7 \mathrm{~cm}$ with gut densely adherent to tumor, stage $3 \mathrm{c}$.

Histopathological examination showed high grade serous carcinoma of bilateral fallopian tube extending upto serosa. Post op period was uneventful and patient discharged on 23-4-13. And reffered to radiotherapy department for chemotherapy.

\section{Case 3}

Mrs C 60 year old P4+0, last child birth 32yr back, was admitted to Kamla Nehru state hospital for mother and child, Shimla on 08-09-2017 with complaint of pain abdomen for 4 month with was gradual in onset localised to lower abdomen and patient also complaint of abdominal distenstion since 4 month patient was menopausal since 10 years on per vaginum examination there was fullness in all fonices no separate mass felt. $\mathrm{Hb}$ was $12.8 \mathrm{gm} \%$, LFT, RFT was normal. CA-125 was $2656 \mathrm{u} / \mathrm{ml}$. CT showed bilateral adenexal mass with multiple metastatic deposit in peritoneum with omental caking with gross ascites? malignant ovarian etiology. Staging laparotomy, peritoneal washing with total 
abdominal hysterectomy with bilateral salpingo oophorectomy, omental biopsy done. Uterus was grossly normal with multiple metastatic deposit on gut uterus, bilateral ovaries, uterovesical fold and bladder. Bilateral fallopian tubes and ovaries were grossly normal.

HPE report showed: left tubal stromainfilterated with tumor cells in sheets, papillae and glands having high $\mathrm{N}: \mathrm{C}$ ratio with numerous mitotic figures and chronic inflammatory cells DIAGNOSIS on histopath was serous carcinoma of left fallopian tube with metastatic deposits in both ovaries and omentum.

Post op period was uneventful .patient discharged and reffered to radiotherapy department for chemotherapy.

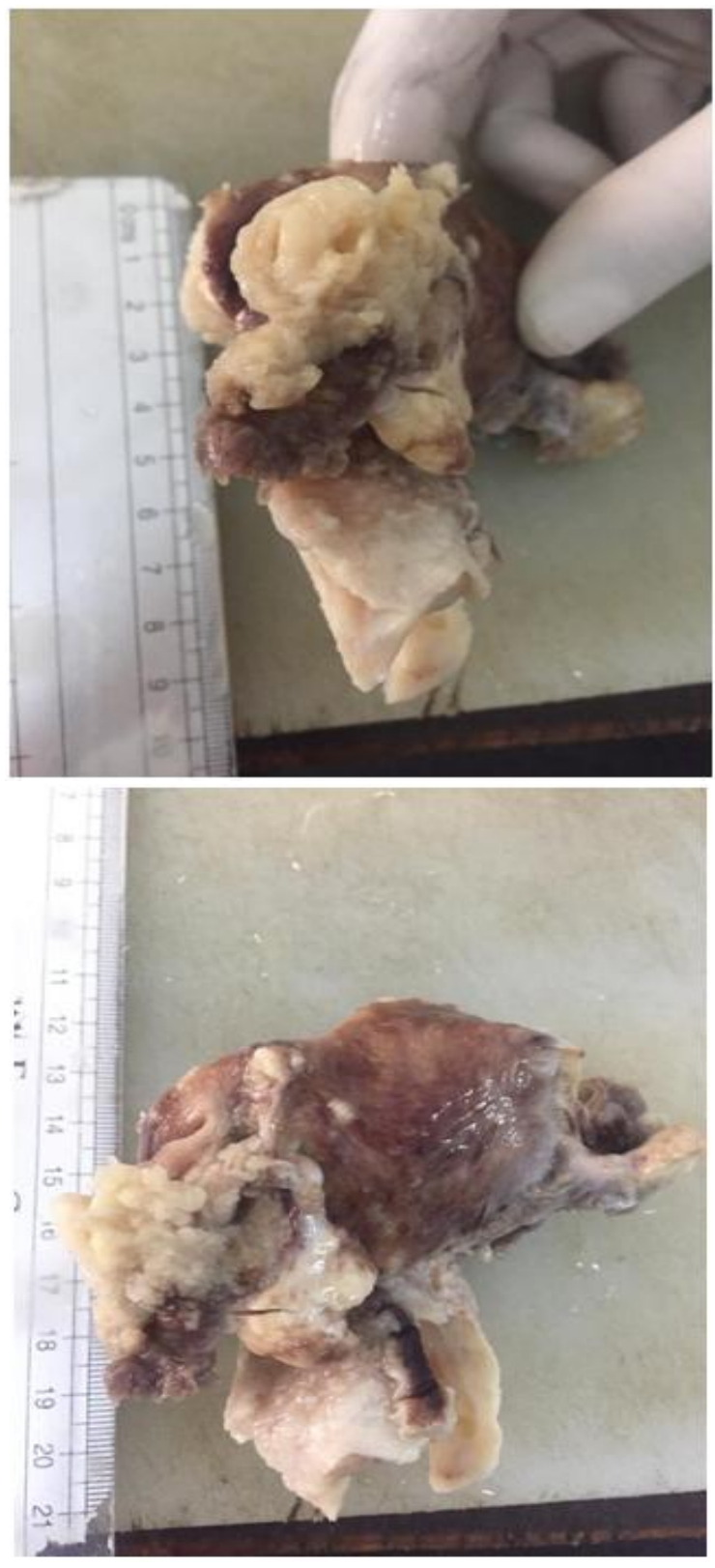

\section{Case 4}

Mrs D 65 year old P4+0, last child birth 35 yr back, was admitted to Kamla Nehru state hospital for mother and child, Shimla on 12-9-18 with complaint of distension of abdomen since 15-20 days gradual onset not associated with pain abdomen. Patient was menopausal since 8 years. Abdomen was tense soon per vaginum examination pelvic organ could not be assessed. Hb13.1gm, LFT, RFT were normal. CA-125 was $4560 \mathrm{u} / \mathrm{ml}$. usg and CT bilateral adenexal masses $2.8 * 2.7 \mathrm{~cm}$ and $1.7 * 1.5 \mathrm{~cm}$ respectively, ovaries not visualised, gross acites. Staging laparotomy, peritoneal washing with total abdominal hysterectomy with bilateral salpingo oophorectomy, omental biopsy done. Uterus was normal, omental caking present multiple metastatic deposit over gut, peritoneum, bladder. Bilateral ovaries and right fallopian tube grossly normal, left fallopian tube has a growth of size $2 * 2 \mathrm{~cm}$ in ampullary region of tube.

HPE report showed that there was evidence of numerous psamoma bodies with tumor invading into the serosa with tumor deposit in muscle coat , ovaries shows metastatic deposits, tumor nodule on omentum . DIAGNOSIS on histopathological examinations was serous carcinoma of left fallopian tbe with tumor deposit on other side fallopian tube, ovary, omentum.

Post op period was uneventful .patient discharged and reffered to radiotherapy department for chemotherapy.

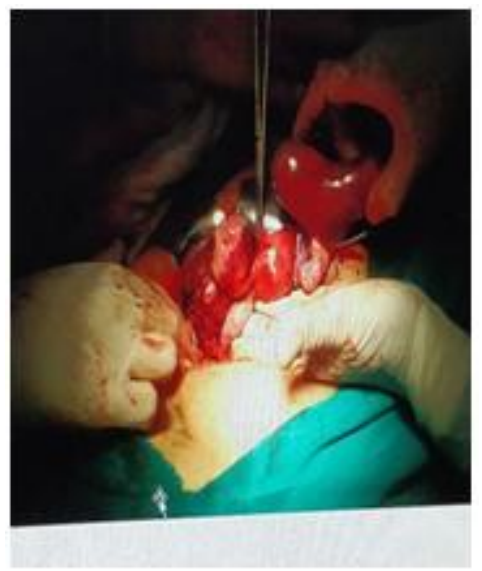



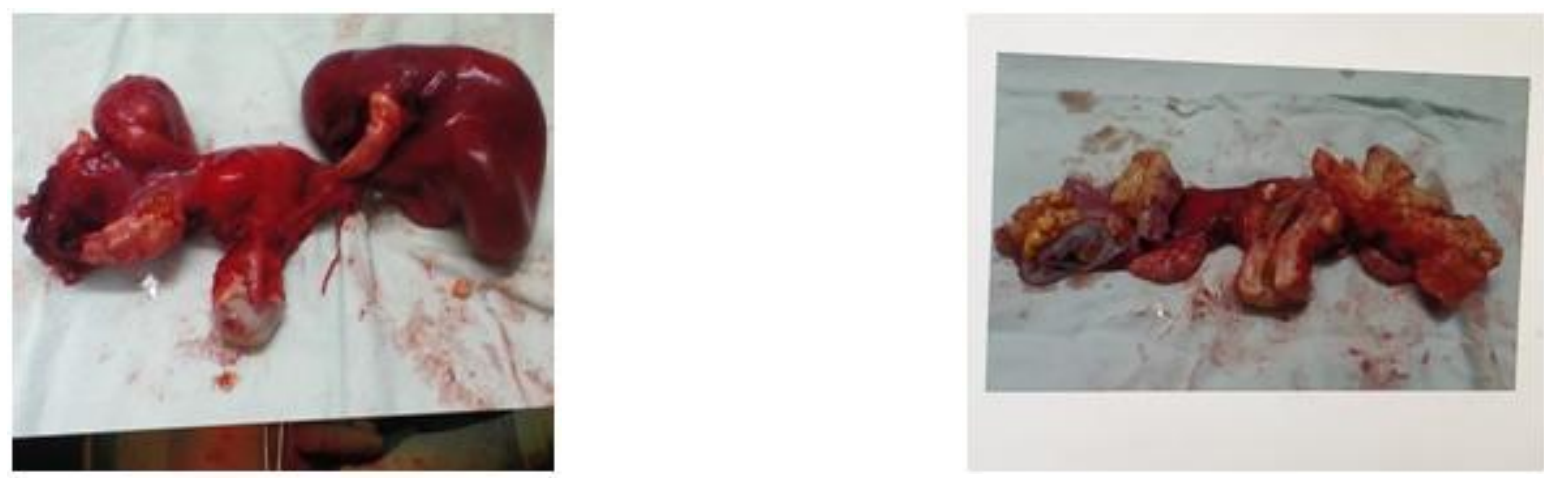

Table 1: FIGO staging of primary fallopian tube carcinoma (PFTC)

\begin{tabular}{|c|c|c|}
\hline STAGE & FIGO CLASSIFICATION & TNM \\
\hline \multirow[t]{3}{*}{0} & Primary tumor cannot be assessed & Tx \\
\hline & No evidence of primary tumor & T0 \\
\hline & Carcinoma in situ (pre-invasive carcinoma) & Tis \\
\hline 1 & Carcinoma confined to fallopian tubes & T1 \\
\hline $1 \mathrm{~A}$ & $\begin{array}{l}\text { Tumor confined to one tube without infiltrating the serosal surface: no } \\
\text { ascites }\end{array}$ & T1a \\
\hline 1B & $\begin{array}{l}\text { Tumor confined to both tubes without infiltrating the serosal surface: } \\
\text { no ascites }\end{array}$ & T1b \\
\hline $1 \mathrm{C}$ & $\begin{array}{l}\text { Tumor confined to one or both tubes with extension onto/through the } \\
\text { tubal serosa or with positive malignant cells in the ascetic fluid or } \\
\text { positive peritoneal washings }\end{array}$ & T1c \\
\hline II & Tumor involving both tubes with pelvic extension & $\mathrm{T} 2$ \\
\hline IIA & Extension and/or metastases to uterus and/or ovaries & $\mathrm{T} 2 \mathrm{a}$ \\
\hline IIB & Extension to other pelvic organs & $\mathrm{T} 2 \mathrm{~b}$ \\
\hline IIC & $\begin{array}{l}\text { Stage IIA or IIB with positive malignant cells in the ascetic fluid or } \\
\text { positive peritoneal washings }\end{array}$ & $\mathrm{T} 2 \mathrm{c}$ \\
\hline III & $\begin{array}{l}\text { Tumor involving one or both tubes with peritoneal implants outside the } \\
\text { pelvis and/or positive regional lymph nodes }\end{array}$ & $\mathrm{T} 3$ and/ or N1 \\
\hline IIIA & Microscopic peritoneal metastases outside the pelvis & T3a \\
\hline IIIB & $\begin{array}{l}\text { Macroscopic peritoneal metastases outside the pelvis } \leq 2 \mathrm{~cm} \text { in greatest } \\
\begin{array}{ll}\text { dimension } & \mathrm{T} 3 \mathrm{~b} \text { and/or } \mathrm{N} 1\end{array}\end{array}$ & $\mathrm{~T} 3 \mathrm{~b}$ \\
\hline IIIC & $\begin{array}{l}\text { Peritoneal metastases more than }>2 \mathrm{~cm} \text { in greatest dimension and/or } \\
\text { positive regional lymph nodes }\end{array}$ & T3c \\
\hline IV & $\begin{array}{l}\text { Distant metastases beyond the peritoneal cavity. Positive pleural } \\
\text { cytology and/or parenchymal liver metastases }\end{array}$ & M1 \\
\hline
\end{tabular}

\section{Discussion}

Primary fallopian tube carcinoma is a rare malignancy and first ever case was described by Renaud in 1847. The PFTC is an underrecognized gynecologic malignancy. In the US the average annual incidence of PFTC is 3.6 per million women per year based on the data analysed from nine population-based cancer registries ${ }^{(5)}$. However the actual incidence may be increasing. In a study from Finland that the ageadjusted incidence of PFTC was 1.2 per million in 1953-1957 which rose to 5.4 per million in $1993-1997^{(6)}$. The International Federation of Gynecology and Obstetrics (FIGO) epithelial ovarian cancer staging system has been adapted to apply to PFTC and is based on the surgical findings at laparotomy as depicted in Table $1^{(4)}$. Generally around $45-50 \%$ patients are diagnosed in stage III $^{(7)}$. It's being a rare entity has made it difficult to define its natural history, etiology, course and optimal treatment and most of the cases reported are either isolated case reports or retrospective studies. In our institution during the past three years, total abdominal hysterectomy with bilateral salpingo-oopherectomy surgeries have been performed and four cases of PFTC have been identified on histology. The exact etiology of PFTC is not known. However, it has been 
postulated that the risk factors including hormonal, reproductive, and genetic factors that increase the risk of epithelial ovarian cancer might also increase PFTC risk. High parity, use of oral contraceptives and a history of pregnancy decreases the PFTC risk significantly ${ }^{(6,8)}$. A fivefold higher bilateral occurrence of PFTC is reported by Meng et al in infertile patients comparing with fertile patients and a better prognosis is reported in nulliparous women ${ }^{(9,10)}$. Other factors like age, race, weight, education level, pelvic inflammatory disease, previous hysterectomy, endometriosis, lactose intolerance, or smoking do not have a statically significant corelation $^{(8,11)}$. A strong association exists with PFTC and families associated with high-risk breast-ovarian cancers with germline BRCA-1 and BRCA-2 mutations ${ }^{(12)}$. Frequently p53 gene alterations are also associated with increased incidence of PFTC ${ }^{(4)}$.

PFTC usually occurs between the fourth and sixth decade of life with a mean age of 55 years. ${ }^{(13,14)}$ similar to our cases. Both the cases were postmenopausal comparable to several other case reports ${ }^{(15)}$. PFTC is rarely asymptomatic. The pathognomonic triad known as the Latzko's triad, is characterized by intermittent, profuse watery vaginal discharge, followed by relief of colicky pain abdomen and disappearance of the pelvic mass ${ }^{(7)}$. Rosen et al said that if vaginal bleeding is the presenting symptom it is associated with longer survival rate irrespective of the stage at which it is diagnosed. This syndrome, Hydropstubaeprofluens, comprises of pelvic mass, profuse watery discharge, pelvic pain that is relieved either spontaneously or by pressure, by passage of pro This is because of the filling and emptying of partially blocked tubal wall ${ }^{(16)}$. In early cases with fimbrial atresia, the intraluminal tubal fluid is discharged through the uterus-vagina route. With open fimbrial end, the tumor cells can spill into the abdominal cavity where they can easily grow. This is usually seen in advanced cases, and the prognosis is rather poor ${ }^{(17)}$. In certain cases, the preoperative diagnosis rarely made. There is a low rate of preoperative diagnosis being around 0\%-10\%. Even intraoperative diagnosis is missed in up to $50 \%$ of patient ${ }^{(9)}$ Besides, even in patients found to have extensive pelvic tumor, a tubo-ovarian mass on histopathologic examination the origin of the tumor may not be clear and usually classified as ovarian in origin being more common than PFTC ${ }^{(9,18,19)}$. fuse serous, watery discharge from vagina. In an another study done by Peter et al reported that a positive peritoneal cytology for malignant cells is the strongest predictor of overall survival .presence of vaginal bleeding associated with longer survival rate is not due to early detection and is not well understood because tumor cells are more angiogenically active and sensitive to anticancerous chemotherapy in advanced disease.

The routine diagnostic work up carried out for gynaecologic malignancies includes ultrasound, CT scan and magnetic resonance imaging (MRI) of the abdomen. The ultrasonographic findings are cystic mass with spaces and mural nodules, a sausage-shaped mass, or a multilobular mass with a cog-and-wheel appearance are similar to other pelvic diseases like tubo-ovarian abscess or ovarian tumo $^{(20)}$. Transvaginal and transabdominal ultrasound is helpful in demonstrating tubal pathology preoperatively in PFTC. A transvaginal ultrasound examination with color Doppler can detect areas of neovascularization within the fallopian tube. Three-dimensional Doppler can show tubal wall irregularities such as papillary protrusions and pseudosepta and depictions of vascular abnormalities. These can be arteriovenous shunts, microaneurysms, tumor lakes, blind ends, and dichotomous branching typical of malignant tumor vessels ${ }^{(21)}$. CT scan or MRI reveals small, solid, lobulated mass. Other findings include peritumoral ascites, intrauterine fluid collection, and hydrosalpinx. The CA-125 antigen is a useful marker in PFTC, though not diagnostic is raised in more than $80 \%$ of patients and also helps in post-treatment follow-up ${ }^{(7)}$.

The diagnosis of PFTC is made on histopathological examination, though the 
differentiation between PFTC and epithelial ovarian carcinoma is difficult. In PFTC, one of the diagnostic criteria should be present a) the main tumour is in tube and arises from the endosalpinx; (b) Histologically, the pattern reproduces the epithelium of the mucosa and often shows a papillary pattern; (c) If the wall is involved, the transition between benign and malignant epithelium should be demonstrable; and (d) The ovaries and endometrium are either normal or contain less tumor than the tube. ${ }^{(4)}$

The treatment of choice is surgical resection followed by chemotherapy. The survival depends upon the stage of PFTC, average being 30\%-50\%. Several chemotherapeutic agents have been used in advanced disease with variable success. These include cisplatin-based chemotherapy and paclitaxel-containing regimens. Harmonotherapy has also been used but is not conclusive.

According to staging it has been shown that 5 year survival rate was $60 \%$ if less than $50 \%$ wall penetrated and survival is less than $20 \%$ if invasion is deeper. Currently recommended surgery is total abdominal hysterectomy with bilateral salpingo-oopherectomy, omentectomy, lymphadenectomy .

Fallopian tube carcinoma is a rare gynaecological tumor. The clinical manifestations are varied and diagnosis is usually made usually intraoperatively and confirmed by histology. A high clinical suspicion in a postmenopausal women, adoption of FIGO 2000 classification will prove beneficial in developing a standardized treatment protocol.

\section{References}

1. Riska A and Leminen A. Updating on primary fallopian tube carcinoma. Acta Obstetricia et Gynecologica Scandinavica 2007; 86( 12): 1419-1426.

2. Mulvany NJ, Arnstein MB, Ryan VA. Prognostic significance of fallopian tube cytology: a study of 99 endometrial malignancies. Pathology 2000; 32:5-9.

3. Bhavani C, Babu PVR, Reddy ES, Neeraja M. Bilateral Primary Fallopian Tube
Adenocarcinoma - A Rare Case. Int J Med Res Rev 2014;2(4):393-396.

4. Pectasides D, Pectasides E, Economopoulos T. Fallopian tube carcinoma. A review. The Oncologist 2006;11:902-912.

5. Rosenblatt KA, Weiss NS, Schwartz SM. Incidence of malignant fallopian tube tumors. GynecolOncol 1989;35:236-239.

6. Riska A, Leminen A, Pukkala E. Sociodemographic determinants of incidence of primary fallopian tube carcinoma, Finland 1953-97. Int $\mathrm{J}$ Cancer2003;104:643-645.

7. Ajithkumar TV, Minimole AL, John MM et al. Primary fallopian tubecarcinoma. Obstet GynecolSurv 2005;60:247-252.

8. Inal MM, Hanhan M, Pilanci $B$ et al. Fallopian tube malignancies: experience of Social Security Agency Aegean Maternity Hospital. Int $\mathbf{J}$ Gynecol Cancer 2004;14:595-599.

9. Meng ML, Gan-Gao, Scheng-Sun et al. Diagnosis of primary adenocarcinoma of the fallopian tube. J Cancer Res Clin Oncol 1985;110:136-140.

10. Hanton EM, Malkasian GD Jr, Dahlin DC et al. Primary carcinoma of the fallopian tube. Am J Obstet Gynecol 1966;94:832839.

11. Demopoulos RI, Aronov R, Mesia A. Clues to the pathogenesis of fallopian tube carcinoma: a morphological and immunohistochemical case control study. Int J GynecolPathol 2001;20:128-132.

12. Rose PG, Shrigley R, Wiesner GL. Germline BRCA2 mutation in a patient with fallopian tube carcinoma: a case report. GynecolOncol 2000;77: 319-320

13. Pal A, Rao R, Gupta KB, Dogra P. A rare case of primary carcinoma of fallopian tube (PFTC) The Indian Practioner 2012;65(2): 109-110.

14. Agrawal R. Malignancy of fallopian tube. Indian J Pathol Microbiol 2015;58:519-20. 
15. Stewart SL, Wike JM, Foster SL, and Michaud F. The incidence of primary fallopian tube cancer in the United States. Gynecologic Oncology 2007; 107(3):392397.

16. Jeung IC, Lee YS, Lee HN, Park EK. Primary Carcinoma of the Fallopian Tube: Report of Two Cases with Literature Review Cancer Res Treat 2009;41(2):11311.

17. Ma and Duan: Clinical and survival analysis of 36 cases of primary fallopian tube carcinoma. World Journal of Surgical Oncology 2014 12:311.

18. Pfeiffer P, Mogensen H, Amtrup F et al. Primary carcinoma of the fallopian tube. A retrospective study of patients reported to the Danish Cancer Registry in a five-year period. Acta Oncol 1989;28:7-11.

19. Woolas RP, Smith JHF, Sarharnis P et al. Fallopian tube carcinoma: an underrecognized primary neoplasm. Int $\mathbf{J}$ Gynecol Cancer 1997; 7:284-288.

20. Kol S, Gal D, Friedman $M$ et al. Preoperative diagnosis of fallopian tube carcinoma by transvaginal sonography and CA-125. GynecolOncol 1990;37:129-131.

21. Kurjak A, Kupesic S, Sparac V et al. Three-dimensional ultrasonographic and power Doppler characterization of ovarian lesions. Ultrasound Obstet Gynecol 2000;16:365-371.

\section{Abbreviations}

FIGO: International Federation of Gynecology and Obstetrics

TNM: Tumor-Nodes-Metastasis. 